\title{
6 THE ROLE OF UBIQUITOUS COMPUTING IN MAINTAINING WORK- LIFE BALANCE: Perspectives from Women in the Information Technology Workforce
}

\author{
Jeria L. Quesenberry \\ Eileen M. Trauth \\ School of Information Sciences and Technology \\ The Pennsylvania State University \\ University Park, PA U.S.A.
}

\begin{abstract}
Transformations in ubiquitous computing and shifts in the domestic nature of home life are placing greater demands on men and women to balance work and life. Although work-life balance has been heavily investigated for many years, the majority of this research gives very little discussion to the role of technology. Thus, the question remains: Can ubiquitous computing address the issues raised by work-life balance? The purpose of this paper is to explore a particular instance of how ubiquitous computing is utilized to maintain work-life balance from the perspectives of women in the information technology workforce.
\end{abstract}

Keywords Ubiquitous computing, IT workforce, gender, under-represented groups, work-life balance, individual differences theory

\section{INTRODUCTION}

In the transition to an information-based global economy, the lines between work and home are blurring as technology reshapes the workplace and the nature of home life evolves. Ubiquitous computing is facilitating dramatic new alternatives for where, when, and how work is accomplished (Hill et al. 2003; Useem 2000). In addition, the domestic nature of home life is evolving. Since the 1940s, women have entered the labor force in growing numbers at a rate of over 200 percent (Riley and McCloskey 
1996). As a result, the labor force consists of more dual-professional couples who have responsibilities for children and elderly dependents, as well as an increase in individuals who have careers, not just jobs (Useem 2000). These transformations are placing greater demands on men and women to balance work and life.

Although work-life balance has been heavily investigated for many years, the majority of this research gives very little discussion to the role of technology. Thus, the question remains: Can ubiquitous computing address the issues raised by work-life balance? The purpose of this paper is to explore a particular instance of how ubiquitous computing is utilized to maintain work-life balance from the perspectives of women in the information technology workforce. The reasons for doing so are twofold. First, it is reasonable to expect that people employed in technical careers are more likely to be surrounded by ubiquitous computing, leading to a higher degree of exposure and expertise with such technologies. Consequently these users serve as an informative case study of the possible projection of these technologies in maintaining work-life balance. Second, although research has found that while men and women both report high levels of work-life imbalance (Duxbury and Higgins 2003; Milkie and Peltola 1999), women commonly do the majority of domestic work (Hochschild and Machung 2003; Perlow 1998). Thus, men and women exhibit different behavior patterns in relation to work-life balance (Mennino and Brayfield 2002). In addition, women in the IT workforce experience higher levels of stress due to work-life imbalance than their male counterparts (Duxberry et al. 1992; Gallivan 2003; Igbaria, et al. 1997). In this paper, we situate the discussion of work-life balance within the context of ubiquitous computing. We then present data from a field study of gender and IT that is directed at understanding the role of ubiquitous computing in maintaining work-life balance. Finally, we present the contribution of this research to theory and practice.

\section{BACKGROUND}

Work-life balance' ${ }^{1}$ reflects an individual's orientation across career roles and noncareer life roles as an incompatible inter-role phenomenon (Duxbury and Higgins 2003; Greenhaus et al. 2002). According to Greenhaus and Beutell (1985), the balance of work and life is "a form of inter-role conflict in which the role pressures from the work and family domains are mutually incompatible in some respect" (p. 77). Greenhaus et al. (2002) explain that work-life balance, contains three components: time balance, involvement balance and satisfaction balance. Time balance means devoting an appropriate amount of time to work and life roles. Involvement balance means deriving an equal level of psychological engagement in work and life roles. Satisfaction balance means deriving an equal level of satisfaction from work and life roles.

${ }^{1}$ Work-life balance or work-family balance is the management of work-family conflict, work-life conflict, work-life interference, and/or work-life convergence. 


\subsection{Consequences of Work-Life Imbalance}

There is a large body of research on the consequences of work-life imbalance, pointing to negative impacts for individuals. From an individual perspective, work-life imbalance has been found to cause job dissatisfaction (Thomas and Ganster 1995), job stress (Judge et al. 1994), and overall poor well-being (Igbaria et al. 1994). A lack of workplace flexibility is also linked to depression (Googins 1991), difficulty in falling asleep and/or staying asleep, changes in appetite, and tension related aches and pains (Guelzow et al. 1991). A recent study of work-life imbalance in the Canadian workforce showed that the stress level from work-life imbalance almost doubled over the past decade. The resulting reduction of sleep and rejuvenating time contributes to psychological and physical illness (McNaughton 2001). Work-life imbalance also has an effect on home and personal lives. Reeves (2001, in Perrons 2003) explains that work-life imbalance can cause home life to become gloomier and more routine as work-life imbalance creates the need for more rigid and fixed timetables and schedules.

Work-life imbalance can also impair organizational effectiveness, primarily by affecting absenteeism, productivity at work, and high turnover rates (Higgins et al. 1994). The majority of these problems arise as a result of child care and family obligations. Parents who are unable to provide adequate and affordable care for their children may experience time lost from work or a decrease in productivity. In addition, interruptions due to family obligations can infringe on work. Duxbury and Higgins (2003) report that employees with high role overload are three and a half times more likely to have high levels of absenteeism due to physical, mental, or emotional fatigue than counterparts with low levels of role overload. The direct and indirect cost of absenteeism due to role overload is estimated to be between $\$ 4.5$ billion and $\$ 6$ billion per year in Canada alone. Another serious impact of work-life imbalance is high turnover rates (Duxbury et al. 1992; Glass and Estes 1997), which are both expensive and disruptive to employers. Duxbury and Higgins report that employees with high role overload are 2.3 times more likely to report high intent to turnover than counterparts with low levels of role overload.

\subsection{Promises of Ubiquitous Computing}

Weiser (1995) first coined the term ubiquitous computing to explain situations where multiple computers are invisible, indistinguishable, and available to an individual throughout a physical environment, and thus woven into the fabric of everyday life. Not only is ubiquitous computing designed to blend into the user's physical surroundings, but the technology is also engineered to help organize and mediate social interactions wherever these interactions occur (Lyytinen and Yoo 2002). Ubiquitous computing also supports work practices and routine activities (Avital and Germonprez 2003; Chae 2003). Thus, ubiquitous computing enables nothing fundamentally new, but makes tasks faster and easier to do, thereby reducing the strain of mental processing (Lyytinen and Yoo 2002; Weiser 1993).

Researchers are just beginning to investigate the role of ubiquitous computing in work-life balance and their results, to date, have been mixed. Zimmerman (2003) found 
that ubiquitous technologies such as cell phones, laptops, and text messaging devices make it easier to balance work and life. Several studies report that telecommuting helps parents to work in the home rather than be away for long periods of time (Beasley et al. 2001; Hill et al. 2003; Sullivan and Lewis 2001). Riley and McCloskey (1996) argue that telecommuting reduces costs and commute time, while increasing productivity and flexibility. On the other hand, researchers have concluded that access to ubiquitous computing can increase stress levels. Duxbury and Higgins (2003) found that 70 percent of 33,000 respondents felt that ubiquitous computing increased their stress levels and workloads. Hill et al. (2003) found telecommuting had a negative relationship on worklife balance. These researchers question whether telecommuting is ideal for work-life balance, especially for families with young children. Frissen (2000) further highlights the complexities by reporting that Dutch families do not explicitly perceive technology as a solution to communication and coordination problems, yet they continue to use these technologies. Furthermore, researchers found that ubiquitous computing causes the line of demarcation between work and private life to blur and call for additional investigation in this area (Perrons 2003; Sullivan and Lewis 2001).

The mixed results of these studies, coupled with the complexities in understanding the role of ubiquitous computing in work-life balance, present an interesting opportunity for research. Therefore, the following research question is explored in this paper: What is the role of ubiquitous computing in maintaining work-life balance by women in the IT workforce?

\section{METHODOLOGY}

Empirical data from an ongoing study of women in the IT workforce was examined for clues to the role of ubiquitous computing in addressing work-life balance. In this study, which has been ongoing since 2000 , in-depth interviews are being conducted with female IT professionals. In the course of these interviews, women discuss their work histories, individual and environmental influences on their decision to enter the IT profession, and societal viewpoints about gender that have affected their career progression.

A consistent theme that speaks directly to opportunities for ubiquitous computing is the uneven playing field with respect to domestic responsibilities. Simply put, when both partners have careers, domestic responsibilities are not usually shared equally and it is the women who most often bear more responsibility. ${ }^{2}$ Given this situation, coupled with the fact that as IT professionals these women would likely have a heightened understanding of and exposure to new technology, it was expected that this population would represent a meaningful context for examining the strengths and weakness of ubiquitous computing in maintaining work-life balance.

${ }^{2}$ While some same-sex couples are included in this research project, the data set is not yet large enough to enable meaningful analysis. Hence, when we refer to "couples" in this paper, we assume them to be heterosexual couples. 
Interview transcripts with 136 women working as IT professionals in Australia/New Zealand, ${ }^{3}$ Ireland, and the United States were examined for comments about the role of ubiquitous computing in addressing work-life balance. Upon examination of these transcripts, 45 were found to have useable comments. ${ }^{4}$ It is these women upon whose voices our analysis is based. Table 1 shows the distribution of respondents by country. The reason for this difference is that the themes of work-life balance and the use of ubiquitous computing to address work-life balance have become more prominent in the interviews as the research project has evolved over time and as ubiquitous computing has evolved. This is evident in the fact that the Australia/New Zealand interviews (which were conducted first) contain the smallest percentage of useful interviews on this topic. Further, women are not specifically asked either about work-life balance or about ubiquitous computing. These themes arise unprompted. While work-life balance issues arise in a majority of the interviews, the use of ubiquitous computing in maintaining work-life balance is mentioned much less frequently.

The women in this study represent a wide range of ages, backgrounds, levels of management responsibility, and degrees of technical specialization. The women range in age from early $20 \mathrm{~s}$ to late $60 \mathrm{~s}$. The ethnic make-up of the women includes Europeans, European-Americans, European-Australians, African-Americans, Asians, Asian-Americans, Indigenous Australians, Hispanic-Americans, and Middle Eastern women. The women have bachelor's degrees, master's degrees, and Ph.D.s. The fields of study include information science, computer science, engineering and information systems, psychology, nursing, communications, mathematics, and liberal arts. Job titles include program/project manager, software architect, quality assurance engineer, IT administrator, system and Web developer, and small IT business owner.

Table 1. Respondent Characteristics

\begin{tabular}{|l|c|c|}
\hline \multicolumn{1}{|c|}{ Country } & Total \# Interviewed & \# Interviews Used \\
\hline Australia/New Zealand & 30 & 6 \\
\hline Ireland & 21 & 9 \\
\hline United States & 85 & 30 \\
\hline Total & $\mathbf{1 3 6}$ & $\mathbf{4 5}$ \\
\hline
\end{tabular}

${ }^{3}$ Women working in IT in both Australia and New Zealand were interviewed as part of a single study (Trauth 2002), hence the two countries are listed together in this discussion.

${ }^{4}$ We do not assume that ubiquitous computing influences work-life balance in a persistent and universal manner, or that all women respond to these technologies in the same way. Likewise, we acknowledge that the interviews not included in this analysis could potentially indicate participants' selective considerations to not adopt or use ubiquitous computing. Although, these are interesting aspects of the data, it is outside the scope of this specific paper, as we focus on the ways ubiquitous computing is used to maintain work-life balance. 
In this study, we employ Trauth's (2002) individual differences theory of gender and IT, which seeks to explain the observed variation in people's relationship to IT and IT careers by gender. Originally applied to the investigation of the under-representation of women in the IT workforce, the theory is concerned with individual differences among women (rather than differences between men and women) in the ways they experience and respond to characteristics of IT work, the IT workplace, and societal messages about gender and IT. This theory focuses on the individual variations among women that result from a combination of individual characteristics, influencing factors, and environmental factors in order to explain the variation in people's relationships to IT and IT careers by gender. To date, this theory has been used to examine the underrepresentation of women in the IT workforce through exploration of the socio-cultural environment that shapes a woman's gender identity and her professional development, and her individual responses to these influences (Morgan et al. 2004; Quesenberry et al. 2004; Trauth 1995, 2002; Trauth et al. 2005, 2004).

\section{RESULTS}

The participants in this study represent a wide range of situations with regard to work-life balance. Some women are the primary source of family income and may have stay-at-home partners. Other women do not have children and view work-life balance in terms of non-child-related factors such as personal responsibilities. To another group of women, work-life balance referred to the strain of elder care of retired parents. Thus, a number of women in our study have chosen nontraditional ways of balancing work and life (i.e., not leaving the workforce to care for domestic responsibilities) and represent a range of work-life balance situations with varying issues and concerns. Several themes about the role of ubiquitous computing in maintaining balance emerged from the interviews and are discussed in the following sections.

\subsection{Asynchronous Communication}

Of the 45 women included in this study, 19 spoke about asynchronous communication, which allows for more flexibility regarding when and how work is conducted. Many participants felt wireless networks, laptops, mobile phones, electronic calendars, and e-mail allow for flexibility that reduces time barriers and allows for greater control over their schedules. This was a particularly significant theme for Irish women since seven of the nine women in this analysis spoke about asynchronous flexibility and the benefits of communicating with coworkers while out of the office. For example, Cara values ubiquitous computing because it allows her to communicate with her office "from all over the world." Likewise, several women spoke about the benefits of communicating with friends and family while in the office. Karen, an Indian woman who lives in Boston, is able to overcome the time zone differences by using her mobile phone during what are work hours in the United States. 
Another positive aspect of asynchronous communication in maintaining work-life balance is the role of telecommuting using ubiquitous computing, including home-tooffice network connections, mobile phones, and conferencing capabilities. Ten women felt that telecommuting made it easier to balance their work and home lives, particularly for women in urban areas. Nancy, who lives in North Carolina, enjoys telecommuting from her home: "I get to make my own hours, I do not have a commute, and I do not have to dress up." Denise, who telecommuted to her previous job in Washington, DC, finds it "very good, for raising young children, supporting a husband, and having a family and home." Kimberly telecommuted to her consulting job in Boston during maternity leave and was one of the few women to be promoted to manager while on leave. For Rose, another Bostonian, it is all about control.

I wanted to stay home. I wanted to have more control over my own schedule... [And be] able to bring in some income, but at a schedule that was much more convenient to me, in terms of care for my daughter and the amount of time I was actually home.

Despite the positive aspects of asynchronous communication via ubiquitous computing in maintaining work-life balance, a number of negative aspects also emerged from the interviews. One such theme is the $24 / 7$ (twenty-four hours a day; seven days a week) work schedule made possible by ubiquitous computing. Researchers have documented this shift with the expansion of the temporal range and amount of working hours (Perrons 2003). This theme was also supported in our analysis. Eight participants discussed how ubiquitous computing has led to a work environment where they are always accessible, something that negatively impacts work-life balance. While this theme was expressed by American and Irish women of all ages, it was most prevalent among women with children. Candace, an American mother, has experienced a growing expectation that employees work extra hours and be "constantly available by computer or phone." She feels this paradigm is incompatible with home life, and gave responsibility "to advances in technology making it possible for people to be continuously on call." Nuala, a project manager in Ireland, shared her dislike for working on weekends and feels a pressure to check her e-mail messages during time away from the office in order to please her managers.

\subsection{Office Relationships and Productivity}

The participants also explained the impact of ubiquitous computing on office relationships and work productivity. Six women, generally in their $30 \mathrm{~s}$, shared examples of how ubiquitous computing is used to build social networks and to interact with coworkers. For example, Alice uses ubiquitous computing to manage difficulties with coworkers that she does not feel comfortable handling in face-to-face situations. She explained that a student at her university created a website with sexual material which she found highly offensive. Alice used her e-mail and mobile phone to communicate with the student, his professor, and the Dean to resolve the issue without awkward faceto-face conflicts. Helen, a self-proclaimed introvert, does not have time to attend social 
functions and feels uncomfortable in such environments. Thus, she uses e-mail to network with others, without participating in after hour activities:

I think a lot of networking is required to further your career in IT, but I am terrible at it. I do not like to meet new people. [Helen]

But you did mention different times [that you got jobs from networking]? [Interviewer]

That was e-mail. It was not personal networking; it just never worked for me. [Helen]

Five women in this study increased their work efficiency through the enhanced information gathering, multitasking, coordination, and transition to new tasks enabled by ubiquitous computing, such as wireless networks, laptops, mobile phones, video conferencing, electronic calendars, and e-mail. Caitlin uses ubiquitous computing to keep track of her work progress and tasks. Doing so allows her to more easily and quickly transition projects to coworkers. Many women also spoke about the benefit of ubiquitous computing to limit the amount of face-to-face communication they have with coworkers. This reduced face-to-face communication makes it quicker and easier to find the necessary information to complete work tasks. Faith uses ubiquitous computing to work more efficiently during the day. In doing so, she remembers key points to discuss at meetings and ensures that she gets credit for her work.

Five women in this study spoke about the negative influences of ubiquitous computing on productivity. These influences center around the difficulties associated with rapid technological innovations and the stress of continuously learning about new technologies. Emily explained that she can see a difference in ubiquitous computing adoption by novice and professional users of technology. In her opinion, novice users are less likely than professional users to quickly learn about new technologies. Jane feels that women who leave the IT workforce inadvertently "deskill" themselves and may find difficulty returning to the IT industry with its pervasiveness of ubiquitous technologies.

\subsection{Personal Life Benefits}

Six women, five of whom were from North Carolina, also spoke about the role of ubiquitous computing in maintaining balance in their personal lives. In this sense, ubiquitous computing is a mechanism for bonding with family and friends through shared interests. Several women spoke about commonalities they found with their children from ubiquitous computing. Their common interest was used as a tool to bond and spend time with family members. June is involved with computers and video games and uses these technologies to spend time with her children. Several women spoke about the ways ubiquitous computing makes it easier to help with personal responsibilities including homework and school projects. Claire uses ubiquitous computing to mentor young girls in various youth societies to build interest in IT. 
I want to encourage things that help girls...to be curious and want to know what is happening underneath [the technology]. What is inside a cell phone? It is really a radio which is why it does not work if there is no antenna within four miles. Knowing a little about the underneath and not [assuming] things are magic and just work.

\section{DISCUSSION}

We define ubiquitous computing as technologies that are effectively invisible, integrated, and available to individuals throughout their environment (Weiser 1995). However, the participants refer to ubiquitous computing as a tool to support their communication and temporal work arrangements. What was most important to these women was the ability to use technology anytime and anywhere. Although this definition is narrower in scope, we believe the findings represent wider aspects of ubiquitous computing. First, the women spoke about multiple technologies, not just a single form, thus reiterating a premise of ubiquitous computing as one person utilizing multiple technologies. Second, the women consider these technologies to be unobtrusive and available as they need them. Finally, the women spoke about the technologies as integrated into their environment and daily lives. Hence, the women demonstrate the premise of ubiquitous computing as embedded in the environment where they are able to move around and naturally interact with the technology while breaking away from a desktop paradigm.

We extend the individual difference theory by focusing on the ways that woman, with a range of work-life balance issues, use ubiquitous computing to address their needs. This theory focuses on the differences within rather than between the genders, and enables a deeper understanding of the range of work-life balance considerations for women and their influence on the use of ubiquitous computing. Thus, in answer to our research question, our data demonstrates that ubiquitous computing has a role in work-life balance with regard to asynchronous communication, office relationships, work productivity, and personal life benefits. A detailed explanation requires a muanced understanding of the range of work-life balance issues and their influence on ubiquitous computing. With regard to asynchronous communication, women in urban areas were more likely to use and value telecommuting. Women who expressed stress from a 24/7 work style typically had children. With regard to office relationships and work productivity, women who were younger in age were more likely to use ubiquitous computing as a social networking tool. Women who were less experienced with technology found the fast-paced change of ubiquitous computing stressful.

The findings presented in this paper highlight several areas for future research. First, additional analysis is needed to identify the role of cultural perspective and societal expectations in the use of ubiquitous computing to balance work and life. The analysis of multiple cultural contexts in this paper suggests differences in societal messages and expectations of women, but very little variance with regard to the use of ubiquitous computing. Likewise, analyzing multiple dimensions will further refine the individual differences theory as it relates to ubiquitous computing use in maintaining work-life balance. Second, additional research is needed to examine how women in 
industries other than IT view and use ubiquitous computing in maintaining work-life balance. These findings would contribute knowledge to a wider understanding of how women in the IT industry compare to women employed in other areas. Finally, additional research is needed to examine how men inside and outside of the IT industry view and use ubiquitous computing to maintain work-life balance. These findings would contribute knowledge to a wider understanding of the role of ubiquitous computing in maintaining work-life balance.

\section{CONCLUSION}

The decrease in productivity levels and the increase in absenteeism and turnover resulting from work-life imbalance have serious consequences for the occupational attainment of workers as well as the financial stability of families (Glass and Estes 1997). Addressing work-life balance is essential for organizations as it has been found to impede work productivity and contribute to employee turnover (Duxbury and Higgins 2003). Thus, addressing work-life balance by making an explicit link between employees' needs and business goals can be a catalyst for changing work practices that benefit employees and employers (Bailyn et al. 1997; Honeycutt and Rosen 1997; PerrySmith and Blum 2000). A crucial step in this process is to think expansively about changing particular work practices and/or the use of ubiquitous computing. The intent of this research is to use a rich data set about women in the IT workforce to identify how they use ubiquitous computing to maintain work-life balance. In doing so, we build on the individual differences theory to demonstrate differences within a gender in their use of ubiquitous computing in addressing a range of interpretations of work-life balance. Continued research is necessary to fully understand how ubiquitous technologies can continue to contribute to positively reshape the workplace and home life.

\section{REFERENCES}

Avital, M., and Germonprez, M. "Ubiquitous Computing: Surfing the Trend in Balance Act," paper presented at the Workshop on Ubiquitous Computing Environment, Cleveland, Ohio, October 24-26, 2003.

Bailyn, L., Fletcher, J. K., and Kolb, D. "Unexpected Connections: Considering Employees" Personal Lives Can Revitalize Your Business," Sloan Management Review (38:4), 1997, pp. 11-19.

Beasley, R. E., Lomo-David, E., and Seubert, V. R. "Telework and Gender: Implications for the Management of Information Technology Professionals," Industrial Management \& Data Systems (101:8/9), 2001, pp. 477-482.

Chae, B. "Ubiquitous Computing for Mundane Knowledge Management: Hopes, Challenges and Questions," paper presented at the Workshop on Ubiquitous Computing Environment, Cleveland Ohio, October 24-26, 2003.

Duxbury, L., and Higgins, C. "Work-liiêe Conflict: Myths Versus Realities, "FMI Journal (14:3), 2003, pp. 16-20.

Duxbury, L. E., Higgins, C. A., and Mills, S. "After-Hours Telecommuting and Work-Family Conflict: A Comparative Analysis," Information Systems Research (3:2), 1992, pp. 173190. 
Frissen, V. A. J. "ICTs in the Rush Hour of Life," The Information Society (16), 2000, pp. 65-75. Gallivan, M. "Examining Gender Differences in IT Professionals' Perceptions of Job Stress in Response to Technical Change," in Proceedings of the 2003 ACM SIGMIS Conference on Personnel Research: Freedom in Philadelphia-Leveraging Differences and Diversity ithe IT Workforce, M. Mandviwalla and E. M. Trauth (Eds.), New York: ACM Press, 2003, pp. 10-23.

Glass, J. L., and Estes, S. B. "The Family Responsive Workplace," Annual Review of Sociology (23), 1997, pp. 289-333.

Googins, B. K. Work/Family Conflicts: Private Lives-Public Responses, New York: Auburn House, 1991.

Greenhaus, J. H., and Beutell, N. J. "Sources of Conflict between Work and Family Roles," Academy of Management Journal (10), 1985, pp. 76-88.

Greenhaus, J. H., Collins, K. M., and Shaw, J. D. "The Relation between Work-Family Balance and Quality of Life," Journal of Vocational Behavior (63), 2002, pp. 510-531.

Guelzow, M. G., Bird, G. W., and Koball, E. H. "An Exploratory Path Analysis of the Stress Process for Dual-Career Men and Women," Journal of Marriage Family (53), 1991, pp. 151-164.

Higgins, C., Duxbury, L., and Lee, C. "Impact of Life-Cycle Stage and Gender on the Ability to Balance Work and Family Responsibilities," Family Relations (43:2), 1994, pp. 144-150.

Hill, E. J., Ferris, M., and Martinson, V. "Does it Matter Where You Work? A Comparison of How Three Work Venues (Traditional Office, Virtual Office, and Home Office) Influence Aspects of Work and Personal/Family Life," Journal of Vocational Behavior (63), 2003, pp. 220-241.

Hochschild, A. R., and Machung, A. The Second Shift, New York: Penguin Books, 2003.

Honeycutt, T. L., and Rosen, B. "Family Friendly Human Resource Policies, Salary Levels, and Salient Identity as Predictors of Organizational Attraction,"Journal of Vocational Behavior (50:2), 1997, pp. 271-290.

Igbaria, M., Parasuraman, S., and Badawy, M. K. "Work Experiences, Job Involvement, and Quality of Work Life among Information Systems Personnel, "MIS Quarterly (18:2), 1994, pp. 175-201.

Igbaria, M., Parasuraman, S., and Greenhaus, J. H. "Status Report on Women and Men in the IT Workplace," Information Systems Management (14:3), 1997, pp. 44-53.

Judge, T. A., Boudreau, J. W., and Bretz, R. D. "Job and Life Attitudes of Male Executives," Journal of Applied Psychology (79:5), 1994, pp. 767-782.

Lyytinen, K., and Yoo, Y. "Issues and Challenges in Ubiquitous Computing," Communications of the $A C M(45: 12), 2002$, pp. 62-65.

McNaughton, A. M. Family-Friendly Workplaces the Case for Supporting Work-life Balance, The Calgary Children's Initiative, Calgary, Alberta, Canada, 2001 (available online at http://www.childrensinitiative.ca/media/FFWP.pdf).

Mennino, S. F., and Brayfield, A. "Job-Family Trade-Offs: The Multidimensional Effects of Gender," Work and Occupations (29:2), 2002, pp. 226-255.

Milkie, M. A., and Peltola, P. "Playing All the Roles: Gender and the Work-Family Balancing Act," Journal of Marriage and the Family (61), 1999, pp. 476-490.

Morgan, A. J., Quesenberry, J. L., and Trauth, E. M. "Exploring the Importance of Social Networks in the IT Workforce: Experiences with the 'Boy's Club,"' in Proceedings of the $10^{\text {th }}$ Americas Conference on Information Systems, E. Stohr and C. Bullen (Eds.), New York, 2004, pp. 1313-1320.

Perlow, L. A. "Boundary Control: The Social Ordering of Work and Family Time in a HighTech Corporation," Administrative Science Quarterly (43:2), 1998, pp. 328-357.

Perrons, D. "The New Economy and the Work-life Balance: Conceptual Explorations and a Case Study of New Media," Gender Work and Organizations (10:1), 2003, pp. 65-93. 
Perry-Smith, J. E., and Blum, T. C. "Work-Family Human Resource Bundles and Perceived Organizational Performance," Academy of Management Journal (12), 2000, pp. 1107-1117.

Quesenberry, J. L., Morgan, A. J., and Trauth, E. M. "Understanding the 'Mommy Tracks': A Framework for Analyzing Work-Family Issues in the IT Workforce," in Proceedings of the Information Resources Management Association Conference, Hershey PA: Idea Group Publishing, 2004, pp. 135-138.

Reeves, R. Happy Mondays: Putting the Pleasure Back into Work, London: Momentum, 2001. Riley, F., and McCloskey, D. W. "GTE's Experience with Telecommuting: Helping People Balance Work and Family," in Proceedings of the 1996 ACM SIGMIS Conference on Personnel Research, New York: ACM Press, 1996, pp. 85-93.

Sullivan, C., and Lewis, S. "Home-Based Telework, Gender and the Synchronization of Work and Family: Perspectives of Teleworkers and Their Co-Residents," Gender, Work and Organizations (8:2), 2001, pp. 123-145.

Thomas, L. T., and Ganster, D. C. "Impact of Family Supportive Work Variables on WorkFamily Conflict and Strain: A Control Perspective," Journal of Applied Psychology (80:1), 1995, pp. 6-15.

Trauth, E. M. "Odd Girl Out: An Individual Differences Perspective on Women in the IT Profession," Information Technology and People (15:2), 2002, pp. 98-118.

Trauth, E. M. "Women in Ireland's Information Industry: Voices from Inside," Eire-Ireland (30:3), 1995, pp. 133-150.

Trauth, E. M., Quesenberry, J. L., and Morgan, A. J. "Understanding the Under Representation of Women in IT: Toward a Theory of Individual Differences," in Proceedings of the 2004 ACM SIGMIS Conference on Computer Personnel Research, M. Tanniru and S. Weisband (Eds.), New York: ACM Press, 2004, pp. 114-119.

Trauth, E. M., Quesenberry, J. L., and Yeo, B. "The Influence of Environmental Context on Women in the IT Workforce," in Proceedings of the 2005 ACM SIGMIS Conference on Computer Personnel Research, M. Gallivan, J. E. Moore, and S. Yager (Eds)., New York: ACM Press, 2005, pp. 24-31.

Useem, J. "Welcome to the New Company Town," Fortune (8:25), 2000, pp. 62-70.

Weiser, M. "The Computer for the Twenty-First Century," in Human Computer Interaction: Toward the Year 2000, R. M. Baecker, J. Grudin, W. A. S. Buxton, and S. Greenberg (Eds.), San Francisco: Morgan Kaufmann Publishers Inc., 1995, pp. 933-940.

Weiser, M. "Hot Topics: Ubiquitous Computing," IEEE Computer (26:20), October 1993, pp. $71-72$.

Zimmerman, E. "Parent-to-Parent: Using Technology to Stay Connected," Sales and Marketing Management (155:7), 2003, p. 58.

\section{ABOUT THE AUTHORS}

Jeria L. Quesenberry is currently a doctoral candidate and research assistant at the School of Information Sciences and Technology in the Center for the Information Society at the Pennsylvania State University. Her research interests include the study of social and organizational aspects of information technology, with particular focus on the role of gender and under-represented groups in the IT workforce. From 1999 to 2002, she served as a consultant at Accenture, specializing in the implementation of enterprise resource planning (ERP) packages for human resource and payroll management systems. In 1999, she earned a B.S. in Decision Sciences and Management Information Systems from George Mason University. Jeria can be reached at jquesenberry@ist.psu.edu. 
Eileen M. Trauth is a professor of Information Sciences and Technology and Director of the Center for the Information Society at the Pennsylvania State University. Her research is concerned with societal, cultural, and organizational influences on information technology and the information technology professions. Eileen's investigation of socio-cultural influences on the emergence of Ireland's information economy is published in her book, The Culture of an Information Economy: Influences and Impacts in the Republic of Ireland. She is currently engaged in a multi-country study of women in the information technology professions in Australia, New Zealand, Ireland, England, and the United States. Eileen has published 8 books and over 100 research papers on her research. She is an associate editor of Information and Organization and serves on the editorial boards of several international journals. Eileen received her Ph.D. and Master's degrees in information science from the University of Pittsburgh and her Bachelor's degree in education from the University of Dayton. Eileen can be reached at etrauth@ist.psu.edu. 